\title{
Experimental design of photo-Fenton process decolorization of Reactive Red 120 by using mathematical statistics models
}

\begin{abstract}
A statistical design of experiments was used to evaluate the potential use of clay catalyst (CuOFeB) during photo-Fenton process in which the concentration of hydrogen peroxide $\left(\mathrm{H}_{2} \mathrm{O}_{2}\right)$, catalyst loading and $\mathrm{pH}$ values were selected as effective experimental factors in the process of dye decolorization. The photo-Fenton oxidation of Reactive Red 120 (RR120) has been investigated using a concentrating solar parabolic reactor with constant solar radiation of $950 \mathrm{~W} / \mathrm{m}^{2}$ during summer period of the year. Under the optimal reaction conditions catalyst showed good catalytic activity in the processes with dye removal over $90 \%$. Also, experiment confirmed that decolorization efficiency depends on the $\mathrm{pH}$ and concentration of $\mathrm{H}_{2} \mathrm{O}_{2}$, wherein better results were achieved under lower $\mathrm{pH}$ values and higher concentration of $\mathrm{H}_{2} \mathrm{O}_{2}$.
\end{abstract}

\section{KEY WORDS}

light fastness, blue wool scale, printing ink, colour change, printability

\author{
Gordana Pucar Milidrag ${ }^{1}$ \\ Milena Bečelić Tomin ${ }^{1}$ \\ Sanja Rapajić ${ }^{3}$, Miljana \\ Prica $^{2}$ (1D, Đurđa Kerkez ${ }^{1}$ (D) \\ Božo Dalmacija ${ }^{1}$ \\ Aleksandra Kulić Mandić
}

${ }^{1}$ University of Novi Sad, Faculty of Sciences, Department of Chemistry, Biochemistry and Environmental Protection, Novi Sad, Serbia

${ }^{2}$ University of Novi Sad, Faculty of Technical Sciences, Department of Graphic Engineering and Design, Novi Sad, Serbia

${ }^{3}$ University of Novi Sad, Faculty of Sciences, Department of Mathematics and Informatics, Novi Sad, Serbia

Corresponding author: Milena Becelic Tomin e-mail:

milena.becelic-tomin@dh.uns.ac.rs

First recieved: 16.10.2018.

Accepted: 28.11.2018.

\section{Introduction}

In the textile industry wastewater is treated with various physical-chemical (coagulation, flocculation, ozonisation, gravity separation, filtration methods, adsorption, etc.) and biological treatments (removal of nitrogen, phosphorus, organic matter etc.) (Chandran, 2016; Urbas et al., 2016; Boczkaj and Fernandes, 2017). Disadvantages of physical and chemical processes are the formation and disposal of sludge, while the presence of traces of heavy metals and substances such as aromatic hydrocarbons in the biological process inhibits the growth of microorganisms, which requires additional treatment that can be expensive and dangerous (Chandran, 2016; Boczkaj and Fernandes, 2017). Therefore, the development of simple, safe, economical, efficient processes that are not harmful to the environment is of great importance. In recent years, advanced oxidation processes (AOPs) have been 
studied in order to apply new methods for the treatment of organic wastewater (Glaze, Kang and Chapin, 1987; Wanget al., 2016) defined AOPs as water treatment processes characterized by generating reactive hydroxyl radicals at room temperature and atmospheric pressure (Pouran, Aziz and Ashri Wan Daud, 2015). Hydroxyl radicals have a high standard redox potential ( $2.8 \mathrm{~V})$, higher than sulphates, chlorine, permanganate, persulphate anion, hydrogen peroxide and ozone, lower only than fluorine (3.03) (Herney-Ramírezand Madeira 2010; Pouran, Aziz and Ashri Wan Daud, 2015; Boczkaj and Fernandes, 2017), as well as a high reaction rate constant ranges from $10^{6}$ to $10^{10} \mathrm{M}^{-1} \mathrm{~s}^{-1}$ (Moreira et al., 2017). The benefits of the AOPs process relative to conventional processes are the transformation of organic compounds to $\mathrm{CO}_{2}$ and $\mathrm{H}_{2} \mathrm{O}$ without the production of sludge, which discards the need for additional treatment. AOPs are useful in the treatment of persistent pollutants resistant to other treatments such as biological (Giannakis et al., 2016; Boczkaj and Fernandes, 2017). In addition, wastewater with very low organic load (in ppb) containing dissolved organic compounds that are difficult to remove can be treated with advanced oxidation processes (Pouran, Aziz and Ashri Wan Daud, 2015; Boczkaj and Fernandes, 2017). Photo-Fenton (or photo-assisted Fenton) process as a part of AOPs involves the use of solar radiation or artificial source of radiation, which increases the rate of degradation of contaminants stimulating the reduction of ferric ion $\left(\mathrm{Fe}^{3+}\right)$ to ferro ion $\left(\mathrm{Fe}^{2+}\right)$. This process shows high efficiency of oxidation of organic pollutants and inactivation of microorganisms in wastewater (Villegas-Guzman et al., 2017). Photo-Fenton process is a combination of iron ions, hydrogen peroxide and solar and $U V / v i s$ radiation $(\lambda<600 \mathrm{~nm})$, which leads to higher production of hydroxyl radicals through the following reactions: i) reduction of $\mathrm{Fe}^{3+}$ to $\mathrm{Fe}^{2+}$ (Equation (1)) and ii) photolysis of hydrogen peroxide at smaller wavelengths (Equation (2)) (Pouran, Aziz and Ashri Wan Daud, 2015; Villegas-Guzman et al., 2017).

$$
\begin{array}{ll}
\mathrm{Fe}(\mathrm{OH})^{2+}+h v \rightarrow \mathrm{Fe}^{2+}+\mathrm{HO}^{\circ} & (\lambda<580 \mathrm{~nm}) \\
\mathrm{H}_{2} \mathrm{O}_{2}+h v \rightarrow 2 \mathrm{HO} & (\lambda<310 \mathrm{~nm})
\end{array}
$$

Also, as a source of iron and ability to extend the range of the solar spectrum to $450 \mathrm{~nm}$, thus allowing further benefit from solar radiation, photosensitive ferrioxalate complexes have been applied in the solar photo-Fenton (Chandran, 2016; Boczkaj and Fernandes, 2017). Moreover, in an acid medium, ferrioxalate photolysis produces $\mathrm{Fe}^{2+}$ ions and more hydrogen peroxide.

Knowing that average solar radiation in Serbia is approximately 40\% higher than the European average, better utilization of solar energy and implementation of solar reactor in this kind of processes is very important and represents challenge for researchers (Pucar Milidrag et al., 2018). For that reason, the aim of this study was to provide optimal process conditions $\left(\mathrm{H}_{2} \mathrm{O}_{2}\right.$, concentration of the catalyst, $\mathrm{pH}$ and concentration of Reactive Red (RR120)) using mathematical models, in order to achieve the best performance of the process as well as high efficiency of decolorization.

\section{Material and methods}

\section{Reagents}

Commercial RR120 (CAS No. 61951-82-4, EC No. 263351-0), $\mathrm{H}_{2} \mathrm{C}_{2} \mathrm{O}_{4}, \mathrm{Fe}\left(\mathrm{NO}_{3}\right)_{3} \cdot 9 \mathrm{H}_{2} \mathrm{O}, \mathrm{H}_{2} \mathrm{SO}_{4}, \mathrm{NaOH}, \mathrm{CuCl}_{2} \cdot 2 \mathrm{H}_{2} \mathrm{O}$ and $\mathrm{H}_{2} \mathrm{O}_{2}(30 \%)$ were obtained from Sigma-Aldrich. All used chemicals were analytical grade and used without further purification. All solutions were prepared with deionised water. Bentonite (Claris-p70), which was used in experiments, is a product of Bentoproduct Ltd. from Šipovo. Molecular structure of the dye is shown in Figure 1.

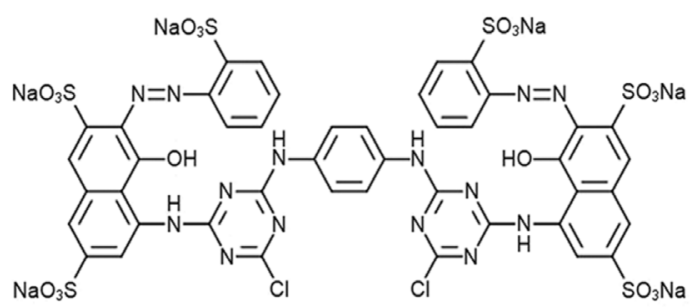

» Figure 1: Molecular structure of RR120

\section{Catalyst preparation}

For preparation of $\mathrm{CuOFeB}$ catalyst, modified methods according to the procedure of Ayodele and Hameed (2013) has been used. CuOFeB was prepared by dissolving $\mathrm{CuCl}_{2} \cdot 2 \mathrm{H}_{2} \mathrm{O}\left(\mathrm{Cu}^{2+}=0.0352 \mathrm{~mol} / \mathrm{dm}^{3}\right)$ and $\mathrm{NaOH}$, maintaining a ratio of $\mathrm{OH} / \mathrm{Cu}=2.25$ and adjusting $\mathrm{pH}=$ 4.1. Then, the prepared solution was easily added to the prepared suspension of clay $(1: 25 \mathrm{~g} / \mathrm{w})$ and stirred continuously for $12 \mathrm{~h}$. After washing the suspension, a solution of $\mathrm{Fe}\left(\mathrm{NO}_{3}\right)_{3} \cdot 9 \mathrm{H}_{2} \mathrm{O}$ and $\mathrm{H}_{2} \mathrm{C}_{2} \mathrm{O}_{4}$ (1:0.832 Fe/oxalate) was added in a suspension of pillared copper bentonite and stirred for $6 \mathrm{~h}$ under heating at $50{ }^{\circ} \mathrm{C}$ in the dark. Then, it was washed and dried at $110{ }^{\circ} \mathrm{C}$ and calcined at $350^{\circ} \mathrm{C}$ for $2 \mathrm{~h}$.

\section{Photoreactor}

Solar photocatalytic experiments were performed in a static parabolic trough collector (Figure 2). The collector consists of a Pyrex glass absorber tube (length 129.70 $\mathrm{cm}$, outer diameter: $1.86 \mathrm{~cm}$, inside diameter: $1.26 \mathrm{~cm}$ ), tracking mechanism and concentrator reflective surface (length $129.70 \mathrm{~cm}$, width of the parabola $113 \mathrm{~cm}$, rim angle $90^{\circ}$ ), with a capacity of $175 \mathrm{~mL}$. The reflector was made of stainless steel sheet. Solar radiation is reflected by the concentrator reflective surface and focused on the absorber tube. The ends of the pipe have valves, one for 
filling a sample of water and another for the sampling. The tracking mechanism enables sunlight to focus on the absorber tube all the time, which is located along the focal line of the concentrator reflective surface.

\section{Photo-Fenton experiments}

The experiments of photo-Fenton process were conducted in the Campus of the University of Novi Sad on an open rooftop (Latitude: $45^{\circ} 14^{\prime} 44.19^{\prime \prime} \mathrm{N}$; Longitude: $19^{\circ} 51^{\prime} 11.29^{\prime \prime} \mathrm{E}$ ) during the summer period (June/July) of the year under clear-sky conditions, with constant solar radiation of $950 \mathrm{~W} / \mathrm{m}^{2}$. The intensity of the solar radiation was kept constant by rotating the collector along its axis and oriented East-South. The maximum time of exposure to solar radiation was $390 \mathrm{~min}$ from 8:30 am to $3 \mathrm{pm}$, followed by centrifuging at $3000 \mathrm{rpm}$ for $5 \mathrm{~min}$. The aliquots were immediately analysed.

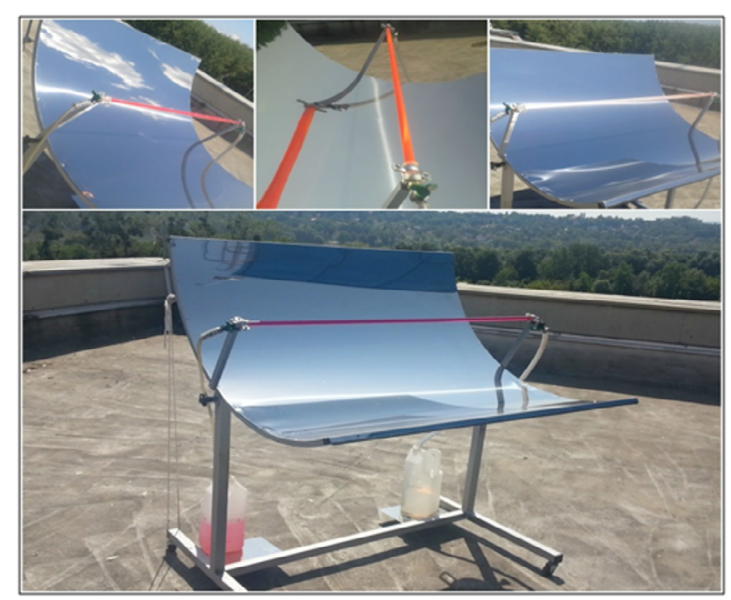

» Figure 2: Solar Parabolic reactor used for photocatalytic experiments

The experiments were performed in the following manner: after adding prepared catalyst (0.01-0.2 g) into the solution of the RR120 (100 mg/L), pH value was adjusted (3-7) and hydrogen peroxide was added (0.625$10 \mathrm{mM}$ ). To ensure contact of the catalyst with the model pollutant RR120, the whole mixture was stirred in the dark on a magnetic stirrer for 5 min before setting in the solar reactor.

The efficiency of dye decolorization was obtained by application of the following formula:

$\mathrm{E}(\%)=\frac{\mathrm{A}_{0}-\mathrm{A}}{\mathrm{A}_{0}} \times 100$

where the $A$ value was received after a certain reaction time and $A_{0}$ is the initial absorbance.

\section{Analytical methods}

Decolorization of the synthetic dye solution was monitored by measuring the absorbance $(A)$ at the wave- length $511.9 \mathrm{~nm}$ using a UV-vis spectrophotometer PG Instruments Ltd. T80 + UV-vis, Model: UV 1800 (Shimadzu, Japan). Measurement of $\mathrm{pH}$ was performed using a pH meter inoLab pH/ION 735 (WTW GmbH, Germany). The intensity of solar radiation was measured by a PL-110SM Solar Radiation Measuring Instrument (Voltsraft, Germany).

\section{Design of experiment}

The operating variables in this experiment were $\mathrm{pH}$ value, $\mathrm{H}_{2} \mathrm{O}_{2}$ concentration and catalysts loading, so experimental runs were conducted based on the combinations of those variables. The response surface analysis provided by Design-Expert 11.0.3. software (Stat-Ease Inc., Mineapolis, USA), is used in order to determine the influence of selected variables on the decolorization efficiency of synthetic dye solution. The range for $\mathrm{pH}$ values was 3-7, while the range for $\mathrm{H}_{2} \mathrm{O}_{2}$ concentration and catalysts loading were 0.625-10 mM and 0.01-0.2 $\mathrm{g}$, respectively. Table 1 shows the fifteen sets of experimental conditions for which the response is obtained.

\section{Table 1}

Experimental design matrix for $\mathrm{CuOFeB}$

\begin{tabular}{|c|c|c|c|}
\hline Run & $\mathrm{pH}$ & $\mathrm{H}_{2} \mathrm{O}_{2}(\mathrm{mM})$ & Catalyst (g) \\
\hline 1 & 3 & 5 & 0.2 \\
\hline 2 & 4 & 5 & 0.2 \\
\hline 3 & 5 & 5 & 0.2 \\
\hline 4 & 6 & 5 & 0.2 \\
\hline 5 & 7 & 5 & 0.2 \\
\hline 6 & 7 & 0.625 & 0.2 \\
\hline 7 & 7 & 1.25 & 0.2 \\
\hline 8 & 7 & 2.5 & 0.2 \\
\hline 9 & 7 & 5 & 0.2 \\
\hline 10 & 7 & 10 & 0.2 \\
\hline 11 & 7 & 5 & 0.01 \\
\hline 12 & 7 & 5 & 0.025 \\
\hline 13 & 7 & 5 & 0.05 \\
\hline 14 & 7 & 5 & 0.1 \\
\hline 15 & 7 & 5 & 0.2 \\
\hline
\end{tabular}




\section{Results and discussion}

\section{Study of the activity and stability of the CuOFeB catalyst}

The advantage of using copper in pillared clays enables to conduct the reaction at higher $\mathrm{pH}$ values, due to its characteristic that it is less sensitive to changes of $\mathrm{pH}$. Also, some authors indicate the occurrence of increased catalytic activity due to presence of copper in pillared clays (Timofeeva et al., 2009). In addition, copper-containing catalysts are considered to accelerate a catalytic reaction due to the generation of a large number of hydroxyl radicals (Ramirez et al., 2010). Therefore, researches were conducted in order to find the optimal concentration of copper and Fe/oxalate ratio, in which high decolorization efficiency is achieved with minimal metal leaching (Cu and Fe). All samples were exposed to the natural light source, under clear-sky conditions. The conditions of the reaction were as follows: [CuOFeB] $=0.2 \mathrm{~g}, \mathrm{pH}=3.5 \mathrm{mM}$ $\mathrm{H}_{2} \mathrm{O}_{2}, 5$ min of stirring, [RR120] $=100 \mathrm{mg} / \mathrm{L}$, Fe/oxalate ratio 1:0.4. Three different copper concentrations were tested: $0.0352 \mathrm{~mol} / \mathrm{dm}^{3}, 0.0704 \mathrm{~mol} / \mathrm{dm}^{3}$ and 0.1408 $\mathrm{mol} / \mathrm{dm}^{3}$. Table 2 shows that at all used concentrations of copper high decolorization efficiency was achieved (about 100\%), however, at the lowest concentration of $0.0352 \mathrm{~mol} / \mathrm{dm}^{3}$ lowest metal leaching occurred.

\section{Table 2}

Application of different copper concentrations

\begin{tabular}{c|c|c|c|c}
\hline $\begin{array}{c}\text { Sample Cu } \\
\left(\mathbf{m o l} / \mathbf{d m}^{3}\right)\end{array}$ & $\begin{array}{c}\mathrm{Cu} \\
(\mathbf{m g} / \mathrm{L})\end{array}$ & Fe (mg/L) & Efficiency (\%) & $\begin{array}{c}\text { Reaction } \\
\text { time (h) }\end{array}$ \\
\hline $\mathbf{0 . 0 3 5 2}$ & 0.189 & 1.031 & 99.67 & \multirow{2}{*}{24} \\
\cline { 1 - 3 } $\mathbf{0 . 0 7 0 4}$ & 0.554 & 3.359 & 99.77 & \multirow{2}{*}{24} \\
\cline { 1 - 3 } $\mathbf{0 . 1 4 0 8}$ & 1.414 & 5.682 & 99.66 & \\
\hline
\end{tabular}

The most stable Fe/oxalate ratio corresponds to a stoichiometric molar ratio of 1:3, in which three bidentate oxalate ions are bound to the center of iron. Lower ratio leads to insufficient oxalate that can lead to a decrease in the yield of the ferro ion regeneration, due to which the lack of oxalate can not form complexes with $\mathrm{Fe}^{3+}$ ions. On the other hand the excess of oxalate can lead to an increase in organic carbon, reduce the penetration of solar radiation, or can be found in competition for hydroxyl radicals, thereby reducing the rate of mineralization of the organic compound (Nogueira et al., 2017; Monteagudo et al., 2010). In order to achieve good process performance using the low Fe/oxalate ratio following researches were performed. The conditions of the reaction were as follows: [CuOFeB] $=0.2 \mathrm{~g}, \mathrm{pH}=3.5 \mathrm{mM}$ $\mathrm{H}_{2} \mathrm{O}_{2}, 5$ min of mixing, $[\mathrm{RR} 12 \mathrm{O}]=100 \mathrm{mg} / \mathrm{L},[\mathrm{Cu}]=0.0352$ $\mathrm{mol} / \mathrm{dm}^{3}$. Three different Fe/oxalate relations (1:1.521; $1: 1.24 ; 1: 0.832)$ were tested in the $\mathrm{pH}$ range of $4.5-6$.
Based on the obtained results at lower Fe/oxalate ratios the decolorization efficiency decreases and duration of the reaction increases (Table 3). Figure 3a,b shows that with decreasing ratio metal leaching reduces. Therefore, the optimum ratio of Fe/oxalate from the aspect of the metal leaching, and achieving high decolorization efficiency, at high $\mathrm{pH}$ values is 1:0.832.

\section{Table 3}

Testing Fe/oxalate ratio at different $\mathrm{pH}$ values

\begin{tabular}{c|c|c|c}
\hline Fe/oxalate & $\mathbf{p H}$ & Time (days) & Efficiency (\%) \\
\hline $1: 1.521$ & 4.5 & 4 & 98.29 \\
\hline $1: 1.521$ & 5 & 5 & 98.53 \\
\hline $1: 1.521$ & 6 & 11 & 98.31 \\
\hline $1: 1.24$ & 4.5 & 3 & 99.41 \\
\hline $1: 1.24$ & 5 & 7 & 99.43 \\
\hline $1: 1.24$ & 6 & 10 & 99.01 \\
\hline $1: 0.832$ & 4.5 & 5 & 98.02 \\
\hline $1: 0.832$ & 5 & 6 & 98.08 \\
\hline $1: 0.832$ & 6 & 13 & 97.80 \\
\hline $1: 0.4$ & 4.5 & 6 & 94.81 \\
\hline $1: 0.4$ & 5 & 7 & 91.77 \\
\hline $1: 0.4$ & 6 & 15 & 88.31 \\
\hline
\end{tabular}
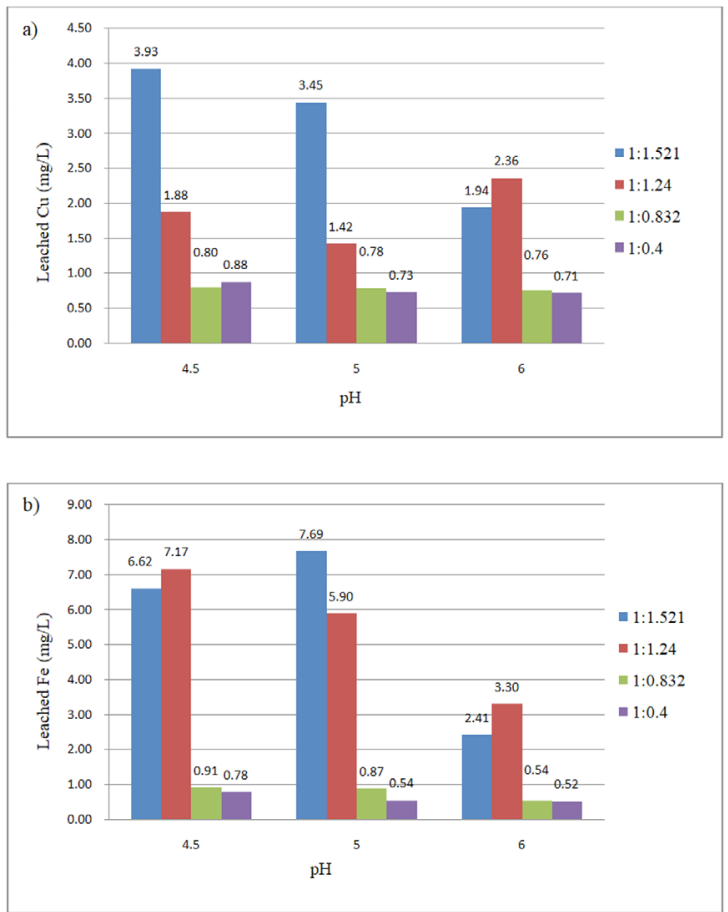

» Figure 3: Concentrations of metal leaching: a) $\mathrm{Cu}$ and b) $\mathrm{Fe}$ 


\section{Optimization of the oprocess using the Design Expert software}

Based on the response obtained for the designed set of operating variables given in Table 4, linear model was analyzed by the Design Expert software as suggested model.

\section{Table 4}

Fit summary based on Sequential Model Sum of Squares

\begin{tabular}{l|r|r|r|r|l|l}
\hline Source & $\begin{array}{c}\text { Sum of } \\
\text { Squares }\end{array}$ & df & $\begin{array}{c}\text { Mean } \\
\text { Square }\end{array}$ & F-value & $\mathbf{p}$-value & \\
\hline $\begin{array}{l}\text { Mean } \\
\text { vs Total }\end{array}$ & $1.005 E+05$ & 1 & $1.005 E+05$ & & & \\
\hline $\begin{array}{l}\text { Linear } \\
\text { Vs Mean }\end{array}$ & $\mathbf{5 4 0 9 . 7 5}$ & $\mathbf{3}$ & $\mathbf{1 8 0 3 . 2 5}$ & $\mathbf{7 . 1 2}$ & $\mathbf{0 . 0 0 6 3}$ & Suggested \\
\hline $\begin{array}{l}\text { 2FI vs } \\
\text { Linear }\end{array}$ & 0.0000 & 0 & & & & Aliased \\
\hline Residual & 2786.78 & 11 & 253.34 & & & \\
\hline Total & $1.087 E+05$ & 15 & 7245.42 & & & \\
\hline
\end{tabular}

The Model F-value of 7.12 and p-value of 0.0063 imply that linear model is significant (Table 5), so this model is used to show the relationship between three independent variables and decolorization efficiency. The statistical significance of model was analysed by ANOVA-analysis of variance. There is only a $0.63 \%$ chance that an F-value this large could occur due to noise. P-values less than 0.05 indicate that model terms are significant. Based on this, Table 5. shows that $\mathrm{H}_{2} \mathrm{O}_{2}$ concentration is the only significant model term.

\section{Table 5}

Obtained ANOVA results for linear model significance

\begin{tabular}{|c|c|c|c|c|c|c|}
\hline Source & $\begin{array}{l}\text { Sum of } \\
\text { Squares }\end{array}$ & df & \begin{tabular}{|c|} 
Mean \\
Square \\
\end{tabular} & F-value & p-value & \\
\hline Model & 5409.75 & 3 & 1803.25 & 7.12 & 0.0063 & significant \\
\hline A-pH & 509.49 & 1 & 509.49 & 2.01 & 0.1839 & \\
\hline $\mathrm{B}-\mathrm{H}_{2} \mathrm{O}_{2}$ & 4302.32 & 1 & 4302.32 & 16.98 & 0.0017 & significant \\
\hline C-Catalyst & 66.33 & 1 & 66.33 & 0.2618 & 0.6190 & \\
\hline Residual & 2786.78 & 11 & 253.34 & & & \\
\hline Lack of Fit & 2786.58 & 9 & 309.62 & 2961.92 & 0.0003 & significant \\
\hline $\begin{array}{l}\text { Pure } \\
\text { Error }\end{array}$ & 0.2091 & 2 & 0.1045 & & & \\
\hline Cor Total & 8196.54 & 14 & & & & \\
\hline
\end{tabular}

As we mentioned, the linear model is chosen to describe the effects of $\mathrm{pH}$ value, $\mathrm{H}_{2} \mathrm{O}_{2}$ concentration and catalysts loading on decolorization efficiency, so experimental data are fitted with linear function, where $Y$ is a percentage of decolorization efficiency, while $\mathrm{A}, \mathrm{B}$ and $\mathrm{C}$ are values of $\mathrm{pH}, \mathrm{H}_{2} \mathrm{O}_{2}$ concentration and catalysts loading, respectively. The obtained regression equation is Equation (4):

$Y=92.55-9.93 A+39.55 B+3.0$
The signal to noise ratio is measured by adequacy precision, which comprised the predicted value at the design points and the average prediction error. As the adequacy precision ratio in this study is 9.6244 (greater than 4), it can be said that it is desirable. So, the developed model can be used in a further study.

The order of runs, the real experimental and predicted values for the efficiency of dye decolorization during the treatment are given in Table 6 . It can be concluded that the actual values for the efficiency of decolorization vary between 30 and $97 \%$. Figure 4 presents constructing diagnostic plots such as predicted versus actual values of the final responses and confirms good agreement between experimental data and model, which points out that linear model is adequate.

\section{Table 6}

Report of predicted and actual values of decolourization efficiency

\begin{tabular}{r|r|r}
\hline Run Order & \multicolumn{1}{|c|}{ Actual Value } & Predicted Value \\
\hline 1 & 97.85 & 102.9 \\
\hline 2 & 97.94 & 97.91 \\
\hline 3 & 97.95 & 92.94 \\
\hline 4 & 97.95 & 87.97 \\
\hline 5 & 97.29 & 83.01 \\
\hline 6 & 30.60 & 46.09 \\
\hline 7 & 37.30 & 51.36 \\
\hline 8 & 55.32 & 61.91 \\
\hline 9 & 97.85 & 83.01 \\
\hline 10 & 97.80 & 125.2 \\
\hline 11 & 63.23 & 76.95 \\
\hline 12 & 69.11 & 77.43 \\
\hline 13 & 95.15 & 78.23 \\
\hline 14 & 95.08 & 79.82 \\
\hline 15 & 97.29 & 83.01 \\
\hline
\end{tabular}

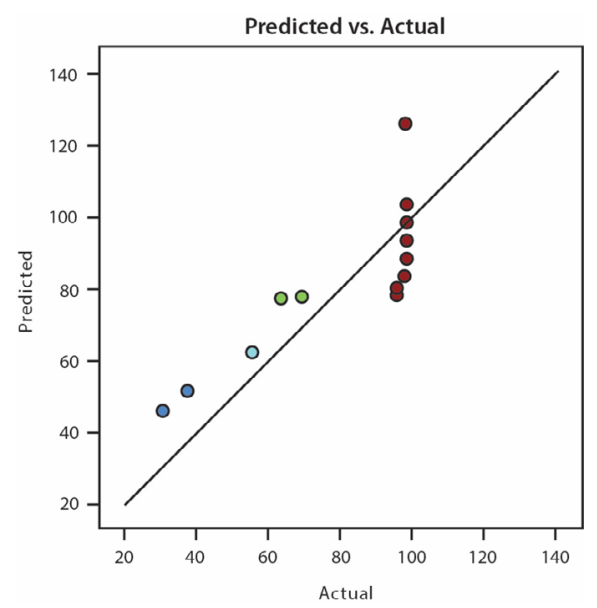

» Figure 4: Predicted vs. actual values for decolorization efficiency 
The effects of operating variables on response can be illustrated by $3 \mathrm{D}$ response surface plots, so the impact of $\mathrm{pH}$ value, $\mathrm{H}_{2} \mathrm{O}_{2}$ concentration and catalysts loading on the decolorization efficincy is presented (Figure $5 a, b$ ).
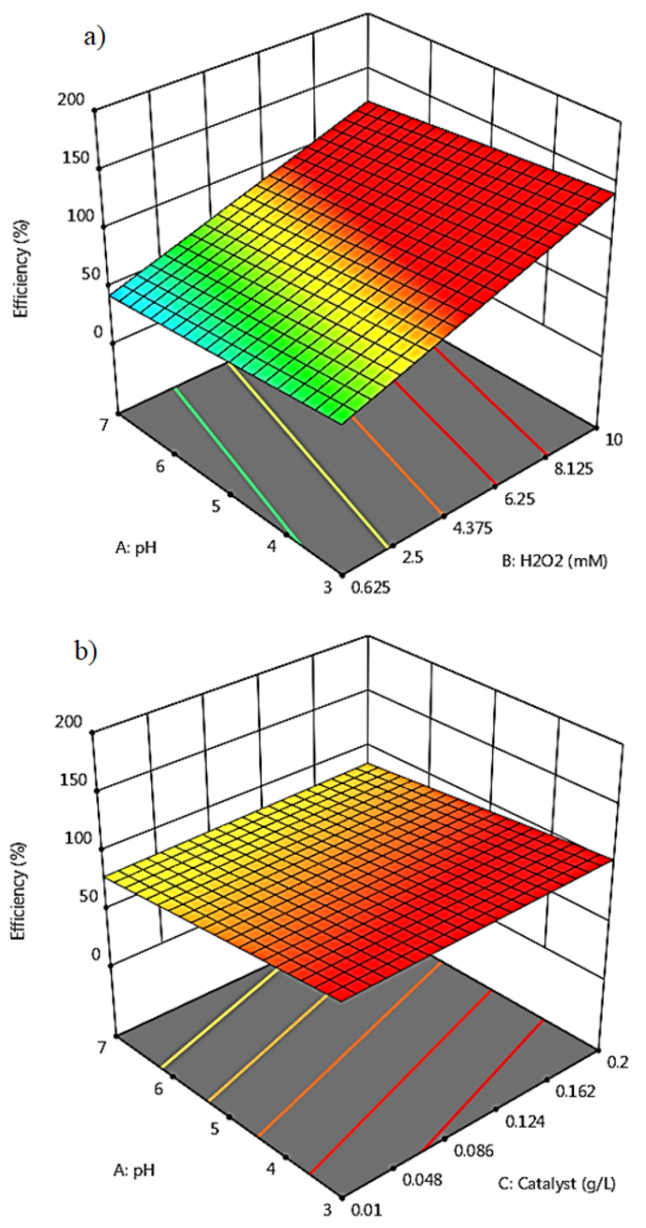

» Figure 5: Decolorization efficiency: a) effect of $\mathrm{pH}$ and $\mathrm{H}_{2} \mathrm{O}_{2}$, b) effect of $\mathrm{pH}$ and catalyst loading

During the photo-Fenton process catalyst $\mathrm{CuOFeB}$ showed a good performance at lower $\mathrm{pH}$ value and higher concentration of $\mathrm{H}_{2} \mathrm{O}_{2}$ (Fig. 5a), while catalyst loading was $0.1 \mathrm{~g}$. Namely, at $\mathrm{pH}$ above 3 , the amount of $\cdot \mathrm{OH}$ radicals decreases due to iron precipitation in the form of iron hydroxide (Huang, et al., 2012). Also, it is well known that the rate of mineralization increases with the availability of $\mathrm{H}_{2} \mathrm{O}_{2}$ achieving its optimal concentration. Any further increase in the concentration of hydrogen peroxide (>10 mM) has a negligible effect on mineralization, because at high concentrations hydrogen peroxide can act as a very invasive scavenger of hydroxyl radicals. On the other hand, at low concentrations of hydrogen peroxide ( $<5 \mathrm{mM})$, sufficient hydroxyl radicals can not be produced to maintain good process performance, and the reaction is much slower or no degradation occurs, since the production of hydroxyl radicals is directly dependent on the concentration of hydrogen peroxide in the solution (Bacardit et al., 2007; Lucas and Peres, 2007; Huang, et al., 2012).
The presence of a catalyst is an important parameter that affects the efficiency of all Fenton processes (Figure 5b). The removal of the dye is directly proportional to the concentration of iron, and depends on the number of active sites, thus directly affecting the efficiency of degradation of the present organic pollutants (Ji et al., 2011). In the heterogeneous Fenton process, increasing the catalyst dose increases the presence of active sites on the surface of the catalysts responsible for the decomposition of hydrogen peroxide and the adsorption of dye molecules (Idel-aouad et al., 2011). Concentration of $\mathrm{H}_{2} \mathrm{O}_{2}$ remind constant and was $5 \mathrm{mM}$. Increasing the $\mathrm{CuOFeB}$ catalyst loading a higher process efficiency occured. Despite the fact that a higher dose of the catalyst in this type of process can also reduce the sunlight penetration through the suspension (Choi and Sakthivel, 2002; Pardeshi and Patil, 2008; Neppolian, Tanveer and Guyern, 2013), the use of $\mathrm{CuOFeB}$ in a given range of catalyst loading in this study did not lead to the screening effect.

\section{Conclusion}

In order to achieve a high efficiency of decolorization, the effects of process parameters $\mathrm{pH}$, concentration of $\mathrm{H}_{2} \mathrm{O}_{2}$ and catalyst loading during photo-Fenton process were investigated using Design Expert software. Based on response surface analysis, $\mathrm{H}_{2} \mathrm{O}_{2}$ concentration was identified as significant factor for decolorization during the process. Also, maintaining neutral reaction conditions, subsequent water neutralization is reduced before discharge into the recipient, therefore $\mathrm{pH}$ 7, $6.8 \mathrm{mM} \mathrm{H}_{2} \mathrm{O}_{2}$ and $0.2 \mathrm{~g}$ of the catalyst can be considered as optimal conditions with acheived decolorization efficiency of 97.95\%. Moreover, additional laboratory experiments should be carried out on the original wastewater sample produced in the process of dyeing using the optimal conditions proposed by the Design Expert software, with the aim to confirm the reliability of the model.

\section{Acnowledgment}

The research was funded by the Ministry of Education, Science and Technological Development (Project III43005 and TR37004).

\section{References}

Asghar, A., Raman, A.A.A. \& Ashri Wan Daud, W.M. (2015) Advanced oxidation processes for in-situ production of hydrogen peroxide/hydroxyl radical for textile wastewater treatment: a review. Journal of Cleaner Production. 87, 826-838. Available from: doi: 10.1016/j.jclepro.2014.09.010

Ayodele, O.B. \& Hameed, B.H. (2013) Synthesis of copper pillared bentonite ferrioxalate cata- 
lyst for degradation of 4-nitrophenol in visible light assisted Fenton process. Journal of Industrial and Engineering Chemistry. 19 (3), 966-974. Available from: doi: 10.1016/j.jiec.2012.11.018

Bacardit, J., Oller, I., Maldonado, M.I., Chamarro, E., Malato, S. \& Esplugas, S. (2007) Simple models for the control of Photo-Fenton by monitoring $\mathrm{H} 2 \mathrm{O} 2$. Journal of Advanced Oxidation Technologies. 10 (2), 219-228. Available from: doi: 10.1515/jaots-2007-0201

Boczkaj, G. \& Fernandes A. (2017) Wastewater treatment by means of advanced oxidation processes at basic $\mathrm{pH}$ conditions: A review. Chemical Engineering Journal. 320, 608-633. Available from: doi: 10.1016/j.cej.2017.03.084

Chandran, D. (2016) A review of the textile industries waste water treatment methodologies. International Journal of Scientific \& Engineering Research. 7 (1), 392-403. Available from: https://www.ijser. org/onlineResearchPaperViewer.aspx?A-REVIEW-OF-THE-TEXTILE-INDUSTRIES-WASTE-WATER-TREATMENT-METHODOLOGIES.pdf

Giannakis, S., López, M.I.P., Spuhler, D., Sánchez Pérez, J.A., Fernández Ibáñez, P. \& Pulgarin, C. (2016) Solar disinfection is an augmentable, in situ-generated photo-Fenton reaction-Part 1: A review of the mechanisms and the fundamental aspects of the process. Applied Catalysis B: Environmental. 199, 199-223. Available from: doi: 10.1016/j.apcatb.2016.06.009

Glaze, W.H., Kang, J.W. \& Chapin, D.H. (1987) The Chemistry of Water Treatment Processes Involving Ozone, Hydrogen Peroxide and Ultraviolet Radiation. Ozone Science \& Engineering. 9 (4), 335-352. Available from: doi: 10.1080/01919518708552148

Herney-Ramírez, J. \& Madeira, L.M. (2010) Use of Pillared Clay-Based Catalysts for Wastewater Treatment Through Fenton-Like Processes. In: Gil, A., Korili, S.A., Trujillano, R., Vicente, M.A. (eds.) Pillared Clays and Related Catalysts. New York, Springer, pp. 129-165. Available from: doi: 10.1007/978-1-4419-6670-4_6

Huang, W., Brigante, M., Wu, F., Hanna, K. \& Mailhot, G. (2012) Development of a new homogenous photo-Fenton process using Fe(III)-EDDS complexes. Journal of Photochemistry and Photobiology A: Chemistry. 239, 17-23. Available from: doi: 10.1016/j.jphotochem.2012.04.018

Idel-aouad, R., Valiente, M., Yaacoubi, A., Tanouti, B. \& Lopez-Mesas, M. (2011) Rapid decolourization and mineralization of azo dye $\mathrm{Cl}$ Acid Red 14 by heterogeneous Fenton reaction. Journal of Hazardous Materials. 186 (1), 745-750. Available from: doi: 10.1016/j.jhazmat.2010.11.056

Ji, F., Li, C., Zhang, J. \& Deng, L. (2011) Efficient decolorization of dye pollutants with LiFe(WO4)2 as reusable heterogeneous Fenton-like catalyst. Desalination. 269 (1-3), 284-290. Available from: doi: 10.1016/j.desal.2010.11.015

Lucas, M.S. \& Peres, J.A. (2007) Degradation of reactive black 5 by Fenton/UV-C and ferrioxalate/H2O2/solar light processes. Dyes and Pigments. 74 (3), 622-629. Available from: doi: 10.1016/j.dyepig.2006.04.005

Monteagudo, J.M., Durán, A., Aguirre, M. \& San Martín, I. (2010) Photodegradation of Reactive Blue 4 solutions under ferrioxalate-assisted UV/solar photo-Fenton system with continuous addition of $\mathrm{H} 2 \mathrm{O} 2$ and air injection. Chemical Engineering Journal. 162 (2), 702709. Available from: doi: 10.1016/j.cej.2010.06.029

Moreira, F.C., Boaventura, R.A.R., Brillas, E. \& Vilar, V.J.P. (2017) Electrochemical advanced oxidation processes: A review on their application to synthetic and real wastewaters. Applied Catalysis B: Environmental. 202, 217-261. Available from: doi: 10.1016/j.apcatb.2016.08.037

Neppolian, B., Choi, H.C. \& Sakthivel, S. (2002) Solar/UV-induced photocatalytic degradation of three commercial textile dyes. Journal of Hazardous Materials B. 89 (2-3), 303-317. Available from: doi: 10.1016/S0304-3894(01)00329-6

Nogueira, A.A., Souza, B.A., Dezotti, M.W.C., Boaventura, R.A.R. \& Vilar, V.J.P (2017) Ferrioxalate complexes as strategy to drive a photo-FENTON reaction at mild $\mathrm{pH}$ conditions: A case study on levofloxacin oxidation. Journal of Photochemistry and Photobiology A: Chemistry. 345, 109-123. Available from: doi: 10.1016/j.jphotochem.2017.05.020

Pardeshi, S.K. \& Patil, A.B. (2008) A simple route for photocatalytic degradation of phenol in aqueous zinc oxide suspension using solar energy. Solar Energy. 82 (8), 700-705. Available from: doi: 10.1016/j.solener.2008.02.007

Pouran, S.R., Aziz, A.A.R. \& Ashri Wan Daud, W.M. (2015) Review on the main advances in photo-Fenton oxidation system for recalcitrant wastewaters. Journal of Industrial and Engineering Chemistry. 21, 53-69. Available from: doi: 10.1016/j.jiec.2014.05.005 Pucar Milidrag, G., Prica, M., Kerkez, Dj., Dalmacija, B., Kulic, A., Tomasevic Pilipovic, D. \& Becelic Tomin, M. (2018) A comparative study of the decolorization capacity of the solar-assisted Fenton process using ferrioxalate and $\mathrm{Al}$, Fe-bentonite catalysts in a parabolic trough reactor. Journal of the Taiwan Institute of Chemical Engineers. [In press: Online] Available from: doi:10.1016/j. jtice.2018.08.015 [Accessed: 30th August 2010].

Tanveer, M. \& Guyern, G.T. (2013) Solar assisted photo degradation of wastewater by compound parabolic collectors: Review of design and operational parameters. Renewable \& Sustainable Energy Reviews. 24, 534-543. Available from: doi: 10.1016/j.rser.2013.03.053

Timofeeva, M.N., Khankhasaeva, S.Ts., Talsi, E.P., Panchenko, V.N., Golovin, A.V., Dashinamzhilova, E.Ts. \& Tsybulya, S.V. (2009) The effect of Fe/Cu ratio in the synthesis of mixed $\mathrm{Fe}, \mathrm{Cu}, \mathrm{Al}$-clays used as catalysts in phenol peroxide oxidation. Applied Catalysis B: Environmental. 90, 618-627. Available from: doi: 10.1016/j.apcatb.2009.04.024 
Villegas-Guzman, P., Giannakis, S., Torres-Palma, R.A. \& Pulgarin C. (2017) Remarkable enhancement of bacterial inactivation in wastewater through promotion of solar photo-Fenton at near-neutral $\mathrm{pH}$ by natural organic acids. Applied Catalysis B: Environmental. 205, 219-227. Available from: doi: 10.1016/j.apcatb.2016.12.021

Urbas, R., Rotar, B., Hajdu, P. \& Stankovič Elesini, U. (2016) Evaluation of the modified braille dots printed with the UV ink-jet technique. Journal of Graphic engineering and design. 7 (2), 15-24.

Wang, N., Zheng, T., Zhang, G. \& Wang, P. (2016) A review on Fenton-like processes for organic wastewater treatment. Journal of Environmental Chemical Engineering. 4 (1), 762-787. Available from: doi: 10.1016/j.jece.2015.12.016

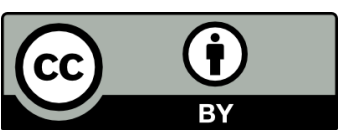

(C) 2018 Authors. Published by the University of Novi Sad, Faculty of Technical Sciences, Department of Graphic Engineering and Design. This article is an open access article distributed under the terms and conditions of the Creative Commons Attribution license 3.0 Serbia (http://creativecommons.org/licenses/by/3.0/rs/). 